Research Article

\title{
Evaluating the Potential of Domestic Animal Manure for Biogas Production in Ethiopia
}

\author{
Fikadu Kumsa Gemechu \\ Biology Department, College of Natural and Computational Science, Ambo University, Ethiopia \\ Correspondence should be addressed to Fikadu Kumsa Gemechu; fikadu422@yahoo.com
}

Received 10 September 2020; Revised 20 October 2020; Accepted 30 October 2020; Published 20 November 2020

Academic Editor: Mohammad Khan

Copyright (c) 2020 Fikadu Kumsa Gemechu. This is an open access article distributed under the Creative Commons Attribution License, which permits unrestricted use, distribution, and reproduction in any medium, provided the original work is properly cited.

\begin{abstract}
Energy is one of the most important needy resources that found in the form of renewable and nonrenewable sources. The world demand for energy grows rapidly, and therefore, it is a time to look alternative and renewable energy resources to replace the rapidly depleting supply of fossil fuels. This study is aimed at analyzing the effects of temperature $\left({ }^{\circ} \mathrm{C}\right)$, retention time (days), and potential of animal waste on the biogas production and its \% $\mathrm{CH} 4$ compositions as responses to the factors of the study. The materials used in this study were cow dung, sheep, and pig manures. Anaerobic batch digesters (plastic water bottle) with a total volume of $2000 \mathrm{ml}$ were used as digester (bioreactor) in this experiment. The glucose drip (tube) was fitted to the lids of each digester. Average temperature of digester was increased starting from the $6^{\text {th }}$ to $10^{\text {th }}$ day in cow dung and sheep manure. In this experiment, optimum time for best biogas yield was recorded. Analysis of the gas component shows the significant volume of methane component recorded in cow dung (66.9\%) followed by sheep manure $(62.1 \%)$. Cow dung was one of the best in producing biogas, while the sheep manure was medium, and pig manures are fewer producers as compared to others.
\end{abstract}

\section{Introduction}

Energy is one of the most important needy resources that found in the form of renewable and nonrenewable sources. Renewable energy sources began to grow more strongly in the early seventies due to the oil crisis that hits the energy market at that time [1]. Biomass is one of the versatile renewable energy sources that can be obtained from trees, timber waste, wood chips, corn, rice hulls, peanut shells, sugar cane, grass cuttings, leaves, manure, sewage, and municipal solid waste $[2,3]$. The world demand for energy grows rapidly, and therefore, it is a time to look alternative and renewable energy resources to replace the rapidly depleting supply of fossil $[4,5]$. Unlike developed country that uses electrical energy to improve their life, the developing country uses firewood for improving their life which results in global warming due to deforestation for firewood. Many countries have realized that biogas is a source of energy which is too much needed for sustainability transition. However, the total production volume of biogas in developing country is still relatively low. Such slow development raises a fundamental question - what are the current barriers hindering the wider uptake of biogas as a source of energy [6]. For instance, biogas was first introduced in Ethiopia by Ambo Agricultural College (Recent Ambo University) around 1957 to supply the energy for welding agricultural tools, and then in the 1970s, two biogas plants were introduced by the Food and Agriculture Organization (FAO) as pilot projects to promote the technology [7].

In Ethiopia, even if the production of biogas started in the last long year, still there are too much need to optimize the biogas resources, adoption, and technologies that will ease the burden for women and children who spend up to 10 hours a week gathering wood in some rural areas to reduce indoor pollution and improve prospects for small farmers [8]. This study is aimed at analyzing the effects of temperature $\left({ }^{\circ} \mathrm{C}\right)$, retention time (days), and potential of animal waste 


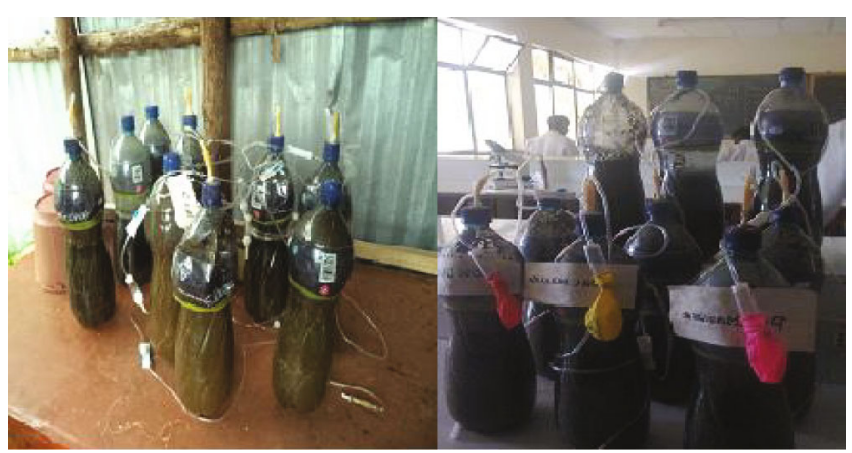

FiguRE 1: Experimental design and setup.

on the biogas production and its \% $\mathrm{CH} 4$ compositions as responses to the factors of the study.

\section{Materials and Methods}

2.1. Materials. The materials used in this study were cow dung, sheep and pig manures.

2.2. Description of the Study Area. This study was conducted at Ambo University which is located in West Shoa Zone Oromia Regional State in Ethiopia and lying between $8056^{\prime} 30^{\prime \prime}-8059^{\prime} 30^{\prime \prime} \mathrm{N}$ latitude and $37047^{\prime} 30^{\prime \prime}-37055^{\prime} 15^{\prime \prime} \mathrm{E}$ longitude. The temperature ranges from $15^{\circ} \mathrm{C}-29^{\circ} \mathrm{C}$.

2.3. Experimental Design and Setup. Anaerobic batch digesters (plastic water bottle) with a total volume of $2000 \mathrm{ml}$ were used as digester (bioreactor) in this experiment. The glucose drip (tube) was fitted to the lids of each digester. The glucose drip bags were used to transfer biogas produced from the digester (Figure 1).

\section{Measurement of Gas Volume}

Gases were collected in gas bags with a volume of 2.5 and balloon $[9,10]$.

3.1. Determination of the Methane Contents. Biogas was measured regularly at set intervals in 30 days. The biogas yields were carried out in accordance with the VDI 4630 guideline of Parajuli [11].

3.2. Experimental Design and Setup. Fresh cow dung and pig manures were collected from Ambo University where cows and pigs are breeding, and sheep manure was collected from Ambo town and around. Equal amount of animal manure were mixed with equal amount of water till the appropriate homogenization is reach (Table 1). Temperatures and $\mathrm{pH}$ of all raw materials (cow dung, sheep manure, and pig manures) were recorded in intervals of five days.

\section{Result and Discussions}

Average temperature of digester was increased starting from the $6^{\text {th }}$ day to $10^{\text {th }}$ day in cow dung and sheep manure. This finding is in agreement with obtaining maximum tempera-
TABle 1: Preparation of digester for biogas production.

\begin{tabular}{lccccccc}
\hline \multirow{2}{*}{ No } & Animal manure & \multicolumn{3}{c}{ Fresh sample weight } & \multicolumn{3}{c}{ Water volume } \\
& & WB1 & WB2 & WB3 & W1 & W2 & W3 \\
\hline 1 & Cow dung & 860 & 860 & 860 & 800 & 800 & 800 \\
2 & Sheep manure & 860 & 860 & 860 & 800 & 800 & 800 \\
3 & Pig manure & 860 & 860 & 860 & 1000 & 800 & 800 \\
\hline \multicolumn{2}{l}{ WB: water bottle; W: water. } & & & & &
\end{tabular}

TABLE 2: Average of temperatures in animal biogas production digester.

\begin{tabular}{lccc}
\hline \multirow{2}{*}{ Days } & \multicolumn{3}{c}{ Average change of temperature } \\
& Cow dung & Sheep manure & Pig manure \\
\hline $1-5$ & $23.86^{\circ} \mathrm{C}$ & $22.16^{\circ} \mathrm{C}$ & $20.9^{\circ} \mathrm{C}$ \\
$6-10$ & $24.66^{\circ} \mathrm{C}$ & $25.04^{\circ} \mathrm{C}$ & $22.8^{\circ} \mathrm{C}$ \\
$11-15$ & $22.1^{\circ} \mathrm{C}$ & $23.06^{\circ} \mathrm{C}$ & $23.5^{\circ} \mathrm{C}$ \\
$16-20$ & $21.6^{\circ} \mathrm{C}$ & $22.0^{\circ} \mathrm{C}$ & $21.1^{\circ} \mathrm{C}$ \\
\hline
\end{tabular}

TABLE 3: Range of $\mathrm{pH}$ in animal manure digesters.

\begin{tabular}{lccc}
\hline Days & Cow dung & $\begin{array}{c}\mathrm{pH} \text { range } \\
\text { Sheep manure }\end{array}$ & Pig manure \\
\hline $1-5$ & 6.88 & 6.00 & 7.00 \\
$6-10$ & 6.00 & 6.50 & 6.80 \\
$11-15$ & 5.40 & 5.80 & 4.90 \\
$16-20$ & 5.10 & 5.50 & 5.10 \\
\hline
\end{tabular}

ture to recover methane gas [12], while the pig digester shows temperature increment at the intervals of $11^{\text {th }}$ day to $15^{\text {th }}$ day (Table 2).

$\mathrm{pH}$ of digester was increased starting from the $1^{\text {st }}$ day to $10^{\text {th }}$ day in all digesters which is similar with previous findings [6], while all the digester shows $\mathrm{pH}$ decrement on the $10^{\text {th }}$ day (Table 3 ).

In the treatment of equal amount of water and sample size, the maximum biogas $(1100 \mathrm{ml})$ was produced from cow dung. Similarly, good quality of biogas was produced from sheep manure. The good quality of methane yield (58\%) from sheep manure was found as optimum value from the previous experiments [13]. But, the list volume $(200 \mathrm{ml})$ of biogas was recorded from pig manure (Figure 2).

In this experiment, optimum time for best biogas yield was recorded. Thus, the best time to recover maximum biogas $(1200 \mathrm{ml})$ from cow dung and sheep manure was on the twelfth day of fermentation, while there was extension time (15 days) to recover maximum gas from pig manure (Figure 3). The finding from this study was similar with studies on effect of retention time on biogas production from poultry droppings and cassava peels and effect of hydraulic retention time on biogas production from cow dung in a 


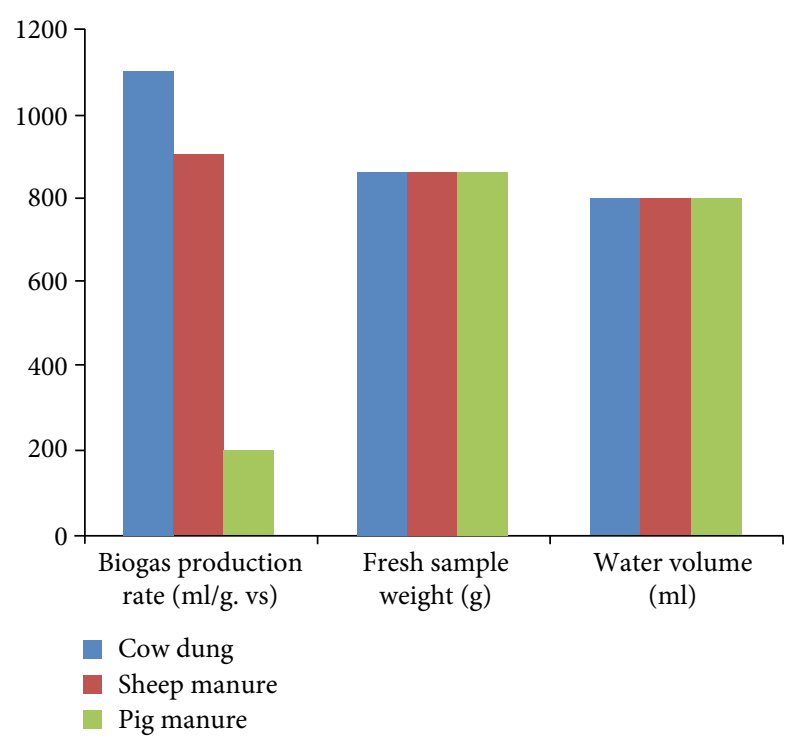

Figure 2: Biogas production rate, size, and item of digesters.

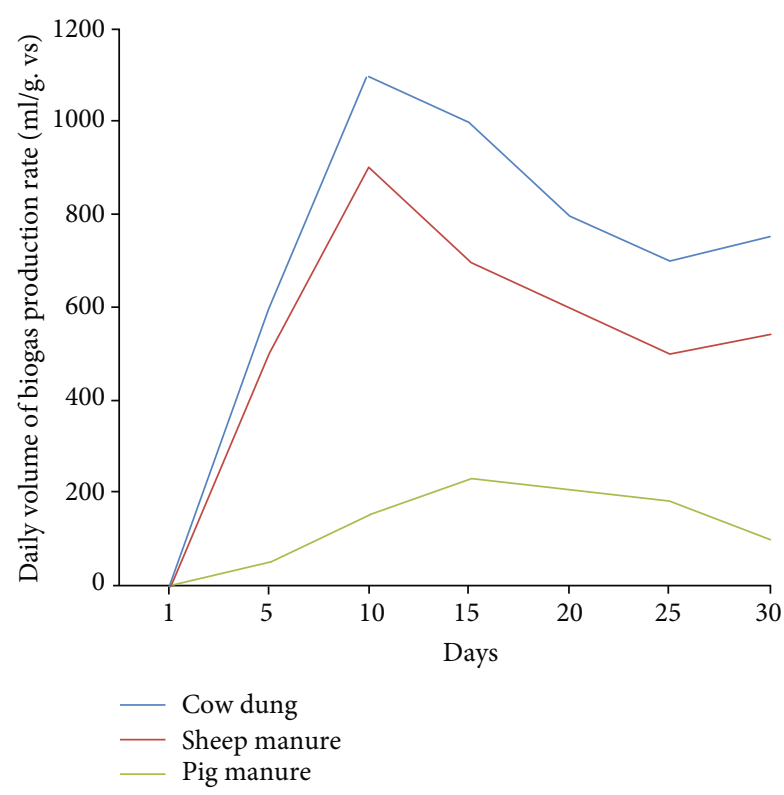

Figure 3: Daily biogas production in three samples.

semicontinuous anaerobic digester, respectively [14, 15]. The changes of temperature in all substrates (cow dung, sheep manure, and pig manure) had an effect on the production of temperature.

Analysis of the gas component shows the significant volume of methane component recorded in cow dung $(66.9 \%)$ followed by sheep manure (62.1\%) [9]. Pig manure has the least $(56.1 \%)$ volume of methane component among the tested substrates (Figure 4).

At room temperature $\left(23^{\circ} \mathrm{C}-28^{\circ} \mathrm{C}\right)$, the biogas from cow dung and sheep manure produced burnable gas after 20 days of retention (Figure 5).

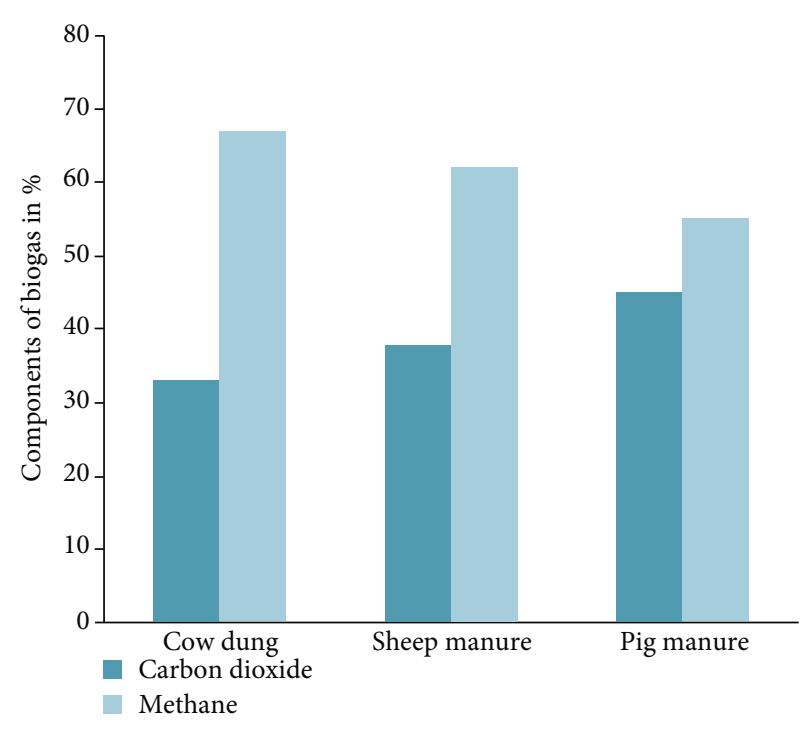

FIgURE 4: Biogas composition by \% volume.

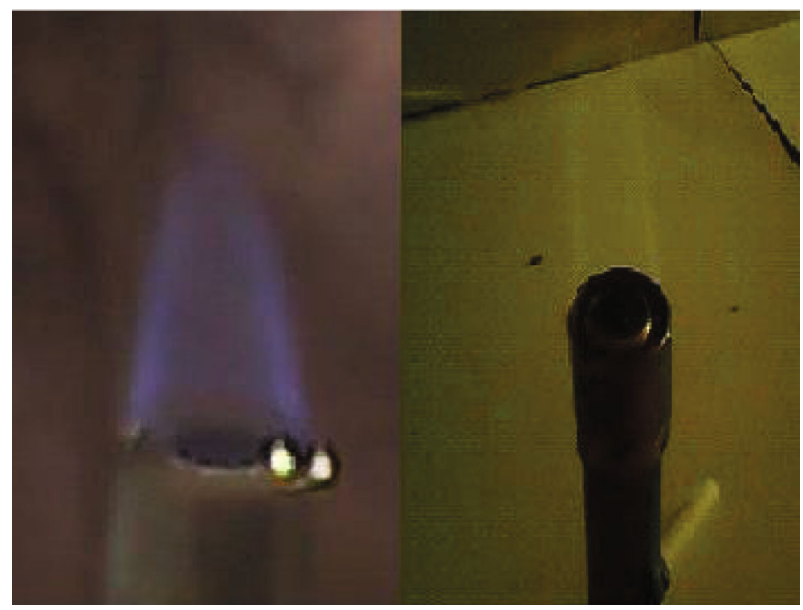

FIgURE 5: Flame of burned biogas.

\section{Conclusion}

The retention time and $\mathrm{pH}$ of the studied animal manures have a correlation with the potential of biogas production. Cow dung was one of the best in producing biogas, while the sheep manure was medium, and pig manure is fewer producers as compared to others.

\section{Data Availability}

I will provide according to its needy.

\section{Conflicts of Interest}

The author declares that there is no conflict of interest regarding the publication of this manuscript. 


\section{References}

[1] T. B. Johansson, H. Kelly, A. K. Reddy, and R. H. Williams, Renewable Energy: Sources for Fuels and Electricity, 1993, http://www.vula.uct.ac.za.

[2] S. M. Ashekuzzaman and T. G. Poulsen, "Optimizing feed composition for improved methane yield during anaerobic digestion of cow manure based waste mixtures," Bioresource Technology, vol. 102, no. 3, pp. 2213-2218, 2011.

[3] D. L. Klass, Biomass for Renewable Energy, Fuels, and Chemicals, Elsevier, 1998.

[4] C. J. BurnsU.S. Patent application no. 29/082,968, 1998.

[5] A. Nansaior, A. Patanothai, A. T. Rambo, and S. Simaraks, "The sustainability of biomass energy acquisition by households in urbanizing communities in Northeast Thailand," Biomass and Bioenergy, vol. 52, pp. 113-121, 2013.

[6] T. Nevzorova and V. Kutcherov, "Barriers to the wider implementation of biogas as a source of energy: a state-of-the-art review," Energy Strategy Reviews, vol. 26, p. 100414, 2019.

[7] J. U. Smith, G. Austin, L. Avery, and B. Balana, “The potential of small-scale biogas digesters to alleviate poverty and improve long term sustainability of ecosystem services in sub-Saharan Africa," in Interdisciplinary Expert Workshop, pp. 4-5, Kampala (Group I) and Addis Ababa (Group II), 2011, http://www.vula.uct.ac.za.

[8] M. G. Mengistu, B. Simane, G. Eshete, and T. S. Workneh, "Factors affecting households' decisions in biogas technology adoption, the case of Ofla and Mecha Districts, northern Ethiopia," Renewable Energy, vol. 93, pp. 215-227, 2016.

[9] K. Arrhenius, A. Fischer, and O. Büker, "Methods for sampling biogas and biomethane on adsorbent tubes after collection in gas bags," Applied Sciences, vol. 9, no. 6, p. 1171, 2019.

[10] B. Rovsek and N. Razpet, "Weight of air in my balloon," 2014, https://www.millersville.edu/physics/experiments/064/index .php.

[11] P. Parajuli, Biogas Measurement Techniques and the Associated Errors, [M.S. thesis], University of Jyväskylä, Finland, 2011.

[12] R. Ramaraj and Y. Unpaprom, "Effect of temperature on the performance of biogas production from duckweed," Chemistry Research Journal, vol. 1, no. 1, pp. 58-66, 2016.

[13] G. Nagy, A. Takács, and A. A. Kállay, "The energy aspects of biogas production from sheep manure," Carbon, vol. 29, pp. 37-70, 2019.

[14] V. A. Ezekoye, B. A. Ezekoye, and P. O. Offor, "Effect of retention time on biogas production from poultry droppings and cassava peels," Nigerian Journal of Biotechnology, vol. 22, pp. 53-59, 2011.

[15] A. Haryanto, S. Triyono, and N. H. Wicaksono, "Effect of hydraulic retention time on biogas production from cow dung in a semi continuous anaerobic digester," International Journal of Renewable Energy Development, vol. 7, no. 2, pp. 93100, 2018. 